of this superiority as "mainly due to superior evaporation in the water hemisphere generally," it did not occur to me that I could be misunderstood to mean that the excessive depression in high south latitudes is due to excessive evaporation taking place zeithin those latitudes, an idea which, with Mr. Murphy, I regard as absurd.

The large areas of depression which the American meteorologists have termed the "Polar Cyclones" appear, on examination, to be themselves aggregates of those local depressions, or cycloncs, which have penetrated either into the Arctic or Antarctic regions, and have there, either partially or wholly, coalesced. Local depressions starting from the edges of the great areas of excessive evaporation seem to be governed in their course by the distribution of relative humidity, and to be determined towards those districts in which precipitation is most in excess of evapo. ration. Consequently their forward development is, as a general rule- a rule to which there are in the northern hemisphere many important exceptions-somephat towards the poles. As they ing commonly expand, and therefore become united, while the influence of the earth's rotation deflects their circulating currents further away from the points of lowest pressure. Mr. Murphy's view that the imperfection of the Arctic as compared with the Antarctic depression, is due to the amount of land in the northern hemisphere, and the local air-currents produced thereby, is not in opposition to my argument. Undoubtedly over Greenland the anticyclonic circulations predominate (except in the summer quarter) over the cyclonic. It is not improbable that somewhat analogous irregularities of pressure dependent on the distribution of land and sea may exist in high south latitudes. But I still think that it is to the middle latitudes of the two hemispheres that we must look in order to find the chief cause of the contrast between the Antarctic and Arctic depressions, for it is in the midale latitudes that the majority of the local depressions originate. In the southern hemisphere those latitudes are almost entirely occupied by surfaces in which evaporation is excessive. In the northern they are represented to a large extent by areas of relatively slight evaporation and predominant precipitation.

The correlation of wind and pressure-distribution is of a kind which can hardiy be stated at the same time briefiy and correctly. But if it is necessary to be concise, it seems more natural in every case to regard the distribution of pressure as the primary cause of the wind than to say "the cause of the depression round the Pole is the centrifugal force of the west winds."

Lutterworth, January 9 W. ClEMENT LEY

\section{Sense of Hearing, \&c., in Birds and Insects}

Mr. Romanes (NATURE, vol. xv., p. I 77) is not quite correct in supposing that the Death's Head is the only species of Lepitoptera known to "stridulate." Possibly the phenomenon is far more general than is commoniy believed, although only few instances of its occurrence have beer observed. In the current number of the Entomologist's Montinly Magazine, Mr. Swinton details the method in which a sound is believed to be produced by Vanessa io and $V$. urtica, viz., by friction of a nervure of the hind-wings against a "filed" nervure in the fore-wings. Chelonia pudica, one of the tiger-moths, has long been known to produce a sound ( $c f$. Solier, Annales Soc. Entomol. de France, produce a sound (cf. Sóler, Ann. Soc. Fr., pp. 398-401) notices the sina possesses a tympaniform organ on each side of the breast, analogous to that found in the Chelonia, and in of the breast, analogous to that found in followed by Laboulbene, who gives an elate anatomical description of the organ in Chelonia, with figures (pl. 10). Another tiger-moth (Eaprepia matronula) is said to stridulate (cf. Czerny, Verhand. zool.-bot. Vereins in Wien, I859); and the existence of the phenomenon is (at least) Wepidoptera.

Without being able to prove it, I suspect that birds obtain a knowledge of the whereabouts of worms and subterranean larva by sight, and not by sound. In the case of the thrush, I think the excrement rejected to the surface guides the bird to the right the excrement rejected to the surface guides the birds almost exclusively on the larvæ of Tipula. Here, again, I think it is sight, and not sound that aids the bird. True, in this case there is no rejected excrement on the surface, but there is something that may be equally significant to the eye of the bird, viz., the withered condition of the plants of grass, \&c., telling a tale of the mischief that is going on below. Furthermore, is it not possible that if the movements of the larvæ below the surface cause sufficient sound to be heard above the surface, the move- mersts of the bird should act as a warnin: and cause the larvo to cease feeding? The withered plant tells its own tale; if only flagging, hut yet with some amount of vitality in it, the chances are that a larva is still at work at its roots ; if entirely dead, then the larva has departed for another plant.

Confessedly in the case of the curlew and allied birds, the matter becomes very difficult of explanation, owing to the depth below the surface at which the food is found. But do these marine and other worms always keep at the depth to which the bird is obliged to penetrate in order to obtain them? Solen is believed to remain near the surface until warned that an enemy is near, when it descends with rapidity. "The wora might also be ordinarily near the surface, and the slight movement thereon caused by its endeavours to bury itself deeper might result in its destruction. I throw this out as a suggestion, because it is hard to believe that sound produced by the movements of an annelid could be transmitted through nearly a foot of sand. There is yet another difficulty. In the case of the curlew the sound would have to travel nearly a foot aboue the suriace before it reached the auditory organs of the bird.

Levisham

ROBER'T M'LACHLAN

\section{THE "CHALLENGER" COLLECTIONS}

THE following "Preamble" to iz list of observing stations, printed for the use of the naturalists engaged in preparing the account of the voyage, contains so much likely to interest naturalists generally that we think it useful to publish it in NATURE:-

The special object of the Challenger Exploring Expedition was to investigate the physical and biological conditions of the great ocean basins; and with this object in view, during an absence from England of three years and $a$ half, and at intervals as nearly uniform as circumstances would permit, throughout a course of 68,890 miles, 362 observing stations were established.

The following list of these stations has been compiled for the use of those naturalists who have consented to assist in the working out of the scientific results of the expedition, with a view to their being published in an official account of the voyage. Interesting observations were made on land as opportunity occurred during the short periods of the Chat?enger's stay in port, and during her short visits to remote islands; but these observations were necessarily desultory and incornplete, and it has been decided to omit their consideration from the present work, and to publish such as may appear of sufficient value in the transactions of learned societies. The Official Report will thus consist strictly of an account of the additions which have been made to the knowledge of the physical and biological conditions of the ocean by the expedition.

At each station the following observations were made, so far as circumstances would permit. The position of the station having been ascertained-

r. The exact depth was determined.

2. A sample of the bottom averaging from $\mathrm{r}$ oz. to $\mathrm{I} \mathrm{lb}$. in weight was recovered by means of the sounding instrument, which was provided with a tube and disengaging weights.

3. A sample of the bottom water was procured for physical and chemical examination.

4. The bottom temperature was determined by a registering thermometer.

5. At most stations a fair sample of the bottom fauna was procured by means of the dredge or trawl.

6. At most stations the fauna of the surface and of intermediate depths was examined by the use of the towinet variously adjusted.

7. At most stations a series of temperature observations were made at different depths from the surface to the bottom.

8. At many stations samples of sea-water were obtained from different depths.

9. In all cases atmospheric and other meteorological conditions were carefully observed and noted. 